\title{
Şehir İçi Deniz Yolu Toplu Taşımacılığında Vapur Atama ve Rotalama Optimizasyonu: İstanbul Şehir Hatları Uygulaması
}

\author{
Ferry Assignment and Routing Optimization for Public \\ Ferry Transportation: A Case Study for Istanbul Şehir \\ Hatlari
}

Eda Yücel ${ }^{*}$ [D

1 TOBB Ekonomi ve Teknoloji Üniversitesi, Mühendislik Fakültesi, Endüstri Mühendisliği Bölümü, 06510, Ankara Sorumlu Yazar / Corresponding Author*: e.yucel@etu.edu.tr

\author{
Geliş Tarihi / Received: 26.07.2018_ DOI:10.21205/deufmd.2019216204 \\ Kabul Tarihi / Accepted: 23.12.2018_Araștırma Makalesi/Research Article
}

Atıf șekli/ How to cite: YÜCEL, E. (2019). Şehir İçi Deniz Yolu Toplu Taşımacıllğında Vapur Atama ve Rotalama Optimizasyonu: İstanbul Şehir Hatları Uygulaması. DEUFMD, 21(62), 357-368.

Öz

Bu çalıșmada, șehir içi deniz yolu toplu tașımacılığında seferlere vapur atama ve rotalama problemi ele alınmıştır. Problem, gerçek hayatta İstanbul Şehir Hatları A.Ş.'nin periyodik olarak karşılaştı̆̆ı, tarifelerde saatleri belirlenen seferlere vapur atama probleminden yola çıkılarak tanımlanmıştır. Sefer tarifeleri, yaz ve kış dönemine ve haftanın günlerine göre farklıllı göstermektedir. Atamada; seferlerin yolcu talepleri, hat-vapur kısıtları, vapurların yolcu kapasiteleri, iskelelerin vapur kapasiteleri, vapurların iskelelere bağlanabilme kısıtları dikkate alınmalıdır. Ayrıca, personellerin günlük çalışma saatini belirleyen kanuni düzenlemeler vapurların çalışma saatlerini kısıtlamaktadır. Amaç, yakıt tüketimi ve dış kaynak kullanımı maliyetlerinden oluşan toplam maliyetleri en küçüklenmektir. Öncelikle, problem için bir matematiksel model geliştirilmiştir. Gerçek boyutlu problem örnekleri için matematiksel modelin yetersiz kalması nedeniyle tabu arama yöntemine dayalı bir sezgisel yöntem geliştirilmiştir. Geliştirilen yöntemin etkinliği gerçekçi veri kümeleri üzerinde gösterilmiştir.

Anahtar Kelimeler: Vapur-sefer atama ve rotalama, Düğüm ve zaman kısıtlı kapasiteli ayrıt rotalama, Deniz yolu toplu taşımacılı̆ı̆, Tabu Arama

\begin{abstract}
In this research, we study the trip-ferry assigment and ferry routing problem that arises in public ferry transportation services. The problem is motivated by the real problem that Istanbul Sehir Hatları Inc. needs to solve periodically while assigning ferries to ferry lines having predetermined tarrifs. Tariffs differ according to the season and day of the week. The trip-ferry assignment should consider passenger demand of ferry lines, line-ferry restrictions, ferry passenger capacities, ferry capacities of piers and ferry-pier restrictions. Additionally, working regulations of ferry personnel restrict ferry working hours. The objective is to minimize total cost of fuel consumption and outsourcing. First, a mathematical model was developed. As the mathematical model is inadequate for solving realistic size problem instances, a tabu search-based heuristic method is proposed. The effectiveness of the heuristic is analayzed on realistic data instances.
\end{abstract}


Keywords: Ferry-trip assigment and ferry routing, Node and time constrained capacitated arc routing, Maritime pupblic transport, Tabu search

\section{Giriş}

Sunulan ulaşım hizmetinin verimliliği maliyet etkinliği üzerinden, kalitesi ise müşteri ihtiyaçlarını karșılanabilirliği üzerinden ölçülmektedir.

Kent içi ulaşım, kent sınırları içinde, insanların veya eşyaların bir yerden başka bir yere emniyetli, güvenli ve hızlı bir biçimde ulaşım sistemleriyle taşınmasıdır. Kentsel ulaşım, toplu ve bireysel ulaşım ile yük taşımacılığından meydana gelmektedir. Kent içi toplu ulașım (taşıma) sistemleri, gerek devlet tarafından gerek özel şirketler tarafından, havayolu, karayolu, demir yolu (raylı sistemler) veya deniz yolu üzerinden kamu yararına sunulan hizmetlerden olușmaktadır. Kentin fiziksel koşulları ve kent büyüklügü̈, seyahat süresi ve yolcuların ulaşım sistemi seçimini etkilemektedir [1].

Denize kıyısı olan şehirlerde deniz taşımacılığı, karayolu trafiğinin olumsuz etkisinden uzak oluşu, düşük maliyetli ve yüksek konforlu ve güvenlikli yolculuk imkânı sunması nedeniyle yoğunlukla tercih edilen bir ulașım türüdür. Örneğin, İstanbul'da her gün 1,6 milyon insan Avrupa ile Asya arasında kitalar arası yolculuk yapmaktadır ve bu yolculukların \%25'i deniz yoluyla yapılmaktadır [2].

Deniz yolu toplu taşımacılığı da, diğer toplu tașıma sistemleri gibi, önceden belirlenmiș hatlara ve sabit güzergâhlara sahiptir. Deniz yolu toplu taşımacılığında, hatlar ve hatlara ait güzergâhlar tarife olarak adlandırılmakta ve tarifeler dönemsel (yaz ve kış gibi) ve haftanın günlerine göre (hafta içi ve hafta sonu gibi) farklılık göstermektedir. Farklı günlerde, farklı güzergâhlara sahip farklı hatların, farklı saatlerde hizmet verdiği bir sistemde hat, güzergâh ve saat tanımlamasından oluşan seferlere vapur atanması gerekmektedir. Atamada; seferlerin yolcu talepleri, hat-vapur kısıtları, vapurların yolcu kapasiteleri, iskelelerin vapur kapasiteleri, vapurların iskelelere bağlanabilme kısıtları dikkate alınmalıdır. Ayrıca, vapur üzerinde 24 saat personel bulunması gerekliliği ve personellerin bir gün içerisinde çalışma saatini kısıtlayan kanuni düzenlemeler vapurların çalışma saatlerini de kısıtlamaktadır.

Literatürde, toplu taşıma hizmetlerine ilişkin yöneylem araştırması alanındaki çalışmalarda; hava yolu $[3,18]$, kara yolu [4], deniz yolu $[5,16]$ ve demir yolu $[6,21,22]$ özelindeki problemlerin ele alındığı görülmektedir.

$\mathrm{Bu}$ çalıșmada, genelde tüm toplu tașımacılık sistemlerinde karşılașllan, özelde ise, deniz yolu üzerinden toplu taşımacılık hizmeti veren kurumların karşılaştığı seferlere vapur atama ve rotalama problemi ele alınmıștır. Problem, gerçek hayatta İstanbul Șehir Hatları A.Ș.'nin periyodik olarak (iki haftada bir) karşılaştığı, tarifelerde saatleri belirlenen seferlere vapur atama probleminden yola çlkılarak tanımlanmıştır. İstanbul Şehir Hatları A.Ş.'nin hizmet verdiği seferler dikkate alındığında oluşan ulaşım ağı Şekil 1'de verilmiştir.

İstanbul Şehir Hatları A.Ș., kıșın 8, yazın 9 ayrı hatta sefer düzenlemektedir. Günlük ortalama sefer sayısının yazın 660, kışın ise 430 olduğu görülmektedir. Mevcut durumda firma, 6 farklı tipte (A, B, C, D, E, F) vapurla hizmet vermektedir. Tablo 1'de verildiği gibi, her vapur tipi farklı bir yolcu kapasitesine sahiptir ve A, B, C, D tipi vapurlar iskelelere yan yanaşırken $\mathrm{E}, \mathrm{F}$ tipi vapurlar iskelelere dik olarak yanaşmaktadır.

Bir vapurun bir hattaki sefere atanabilmesi için ilgili hat ile vapur tipinin uyumlu olması gerekmektedir. Ortalama yakıt tüketim miktarı ise vapur tipinin yanı sıra vapurun yașı gibi faktörlere de bağlı olduğu için vapur bazında değişiklik göstermektedir. Vapurlara ekip atamaları da 2 haftalık periyodlar halinde gerçekleștirilmekte ve her ekip 2 hafta boyunca kesintisiz olarak atandı ̆̆ı vapurda çalıșmaktadır. $\mathrm{Bu}$ nedenle personel çalışma saatlerine ilişkin düzenlemeler vapurların çalışma ve dinlenme saatlerini belirlemektedir. $\mathrm{Bu}$ doğrultuda, vapurlar günlük en fazla 14 saat çalışabilir. Herhangi bir vapur en fazla 8 saat aralıksız çalışabilir. Herhangi bir vapur dinlenmeye başlarsa en az 2 saat dinlenmek zorundadır. Bir vapur dinlenmelerinin birinde en az 6 saat kesintisiz dinlenmelidir. Seferlerde 38 farklı iskeleye hizmet verilmekte olup her iskelenin farklı vapur tipleri için farklı kapasiteleri vardır. $\mathrm{Bu}$ iskeleler yapısına ve kullanım amacına göre sınıflandırılmaktadır (bkz. Tablo 2). Yapısına göre, tek yüzlü ve üç yüzlü iskeleler bulunmaktadır (bkz. Şekil 2). Tek yüzlü iskelelere farklı yanaşma şekillerine sahip vapur tipleri aynı anda yanaşamamaktadır. Amacına göre ise, çalışma ve dinlenme iskeleleri mevcuttur. Dinlenme iskeleleri seferler devam 
ederken vapurların dinlenebildiği iskelelerdir. Calıșma iskelelerine ise, seferler devam ederken vapurlar dinlenmek maksatlı yanaşma yapamamaktadır. Mevcut vapurların yetersiz kalması halinde, maliyeti yüksek olan sefer bazında vapur kiralama seçeneği kullanılmaktadır. Toplam maliyet, vapurların seyahatlerine bağlı oluşan yakıt maliyetleri ve kiralamalara bağlı olușan dıș kaynak kullanımı maliyetleridir. Mevcut durumda, firmada vapur atamasındaki karar süreci insan eliyle yapılmaktadır ve vapurların etkin kullanılamamasına ve toplam maliyetlerin yüksek olmasına neden olmaktadır. Çalışmamızın amacı, sonlu (2 haftalık) planlama çevreninde sefer-vapur atamalarının maliyet etkin olarak gerçekleștirilmesi ve vapurların nerede, ne zaman, ne kadar dinleneceğinin belirlenmesidir.

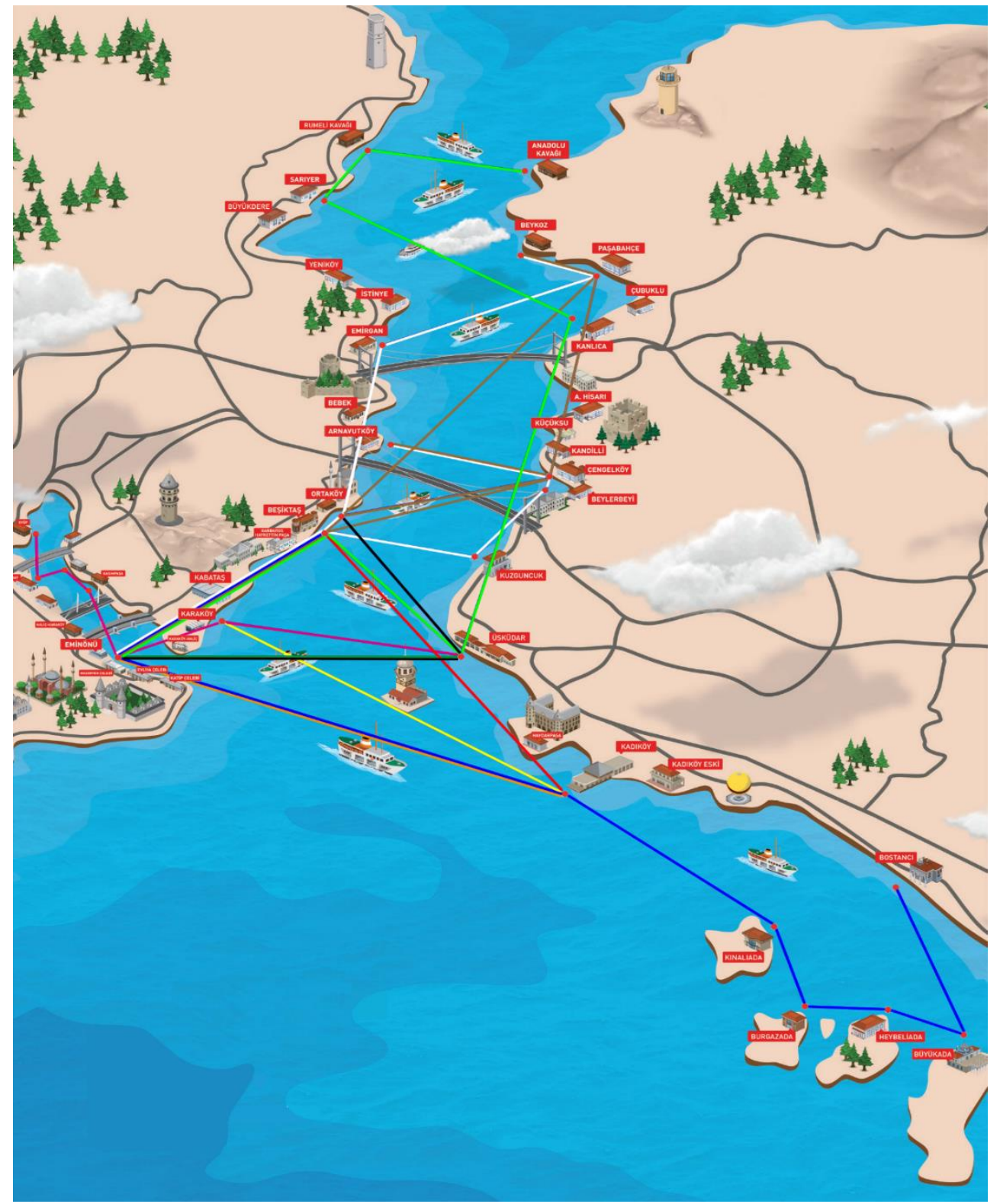

Şekil 1. İstanbul Şehir Hatları A.Ş.'nin servis verdiği seferlerin oluşturduğu ulaşım ağı 


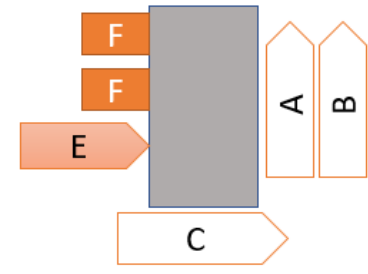

(a) Üç Yüzlü

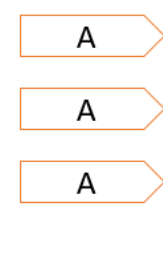

(b) Tek Yüzlü
Şekil 2. Yapısına göre iskele tipleri

Makalenin devamında, Bölüm 2'de ilgili literatür taramasına, Bölüm 3'te problem tanımına yer verilmiştir. Problem için geliştirilen matematiksel model Bölüm 4'te, sezgisel yöntem ise Bölüm 5'te anlatılmıștır. Bölüm 6'da önerilen yöntemlerin hesaplamalı analizlerine ilișkin sonuçlar verilmiştir. Son olarak, Bölüm 7'de ise yapılan çalışmaya ilişsin bulgular özetlenmiştir.

\section{Literatür}

Çalıșma kapsamında ele alınan problem temelde, taleplerin ayritlar üzerinde bulunduğu bir ağ üzerinde tüm talepleri karşlayacak şekilde kapasite kısıtı olan araçların rotalanmasını hedefleyen kapasiteli ayrıt rotalama problemleri sınıfında yer almaktadır. Literatürdeki kapasiteli ayrıt rotalama çalışmaları üzerine ayrıntılı tarama Eiselt vd.'nin çalışmalarında [7, 8] yer almaktadır. Literatür taraması kapsamında, gerek Eiselt vd.'nin taramalarında $[7,8]$ yer alan çalışmalar, gerekse ele alınan probleme benzer nitelikler taşıyan vapur çizelgelemesi ve hava yolu çizelgelemesi çalışmaları incelenmiştir. Problem ile çeşitli özellikleri ile benzerlik taşıyan çalışmalar ve bu çalışmaları yapılan çalışmadan ayıran özellikler aşağılda yer verilmiştir.

Kapasiteli ayrıt rotalama problemleri sınıfına giren sokak temizleme [9], kar kürüme [10], posta dağıtımı [11] ve sayaç okuma [12] problemleri, bu çalışmadaki probleme benzer șekilde rotalama maliyetlerini de içeren toplam maliyetlerin en küçüklenmesi hedeflenmektedir. Ancak bu problemleri ele alan çalışmalarda taleplerin bulunduğu ayritlarda zaman penceresi bulunmaması ve düğümlerde kapasite kısitı olmaması, seferlerde katı zaman pencereleri bulunan ve iskelelerde vapur kapasite kısitı bulunan problemimizden ayrılmaktadır.

Literatürde, araçların depoya dönme zorunluluğu bulunmayan ayrit rotalama problemleri açık ayrıt rotalama problemleri olarak adlandırılmaktadır [13]. Ele alınan problemde de vapurların planlama çevreni sonunda başlangıç deposuna dönme gibi bir zorunlulukları yoktur. Usberti vd. [13]'nin çalışmasında açık kapasiteli ayrıt rotalama problemi ele alınmış ve rotalama maliyetlerinin en küçüklenmesi hedeflenmiştir. Çözüm yöntemi olarak önce grupla sonra rotala sezgiseli önerilmiştir. Ancak Usberti vd. [13]'nin çalışmasında, bu çalışmadaki problemden farklı olarak, taleplerin bulunduğu ayrıtlarda zaman penceresi bulunmamaktadır.

Kapasiteli ayrıt rotalama çalıșmalarından bir bölümünde $[14,15,16]$, bu çalışmadaki probleme benzer şekilde araç filosu heterojendir. Bu çalıșmadaki problemden farklı olarak, Ulusoy [14] standart kapasiteli ayrıt rotalama probleminde heterojen filo oluşturma ve rotalama problemine, Cattrysse [15] ise heterojen araç filosu varlığında ayrıt rotalama uygulamalarında bölge oluşturma problemine odaklanmıștır. Bu çalıșmada ele alınan probleme benzer şekilde, Sniezek [4] heterojen araç filosu varlığında, araç-sefer kısıtlı, kapasiteli ayrıt rotalama problemini ele almıștır. Ancak bu çalışmadaki problemden farklı olarak araç filosu oluşturulması hedeflenmiştir.

Hava yolu taşımacılığında karșılaşılan kapasiteli ayrit rotalama probleminin ele alan Kepir vd. [3]; çizelge (tarife) oluşturma, filo atama, bakım planlama ve ekip atama aşamalarından oluşan dört aşamalı uçuş çizelgeleme probleminin birinci aşaması olan tarife oluşturma aşamasına odaklanmışlardır. Uçakların konumları, havaalanlarının açılış, kapanış saatleri ve kaldırabildikleri uçak sayısı gibi kısıtlar çalışmamızda ele alınan problem ile benzerlik göstermektedir. Ancak, Kepir vd. [3]'den farklı olarak bu çalışmada ele alınan problem surecin ikinci aşaması olan filo atama aşamasına odaklanmaktadır. Orhan vd. [17] havayolu operasyonlarında planlama ve çizelgeleme așamalarını detaylı olarak anlatmaktadır. Deniz yolu ve hava yolu taşımacılığında karşılaşılan filo atama problemleri arasındaki temel farklılıklar şunlardır; Kent içi deniz yolu taşımacılığında planlama daha kısa dönem için (örn., 2 haftalık) yapılır ve bu nedenle planlama döneminde araç bakımlarının ihmal edilebilir, planlama döneminde araca tek bir ekip atanır ve ekip dinlenme ihtiyacl nedeniyle araç dinlenme kısıtlarının bulunur.

Demir yolu taşımacılığında karşılaşılan stratejik, taktiksel ve operasyonel problemler için de yöneylem araştırması yöntemlerinden 
faydalanılmıștır. $\mathrm{Bu}$ çalışmalardan yolcu taşımacılığı alanındakiler için detaylı bir gözden geçirme çalışması Huisman vd. [6] tarafından sunulmuştur. Burada, çeşitli özellikleri ile bu çalışmada ele alınan probleme benzerlik gösteren çalışmalara değinilecektir. Bach vd. [21] demir yolu yük taşımacılığında haftalık tarifelerin oluşturulması ve tarifeli seferlere motor atanması problemini çalışmış ve problemi, tarifelerin oluşturulması ve motor atamalarından oluşan iki probleme ayrıștırarak çözen sütun türetme yöntemini geliștirmişlerdir. Ancak, bu çalışmadaki problemden farklı olarak Bach vd. [21]'nin çalışmasında talebe bağlı olarak seferlere birden fazla motor atanabilmektedir ve motor-istasyon kisitları bulunmamaktadır. Yakın geçmişte, Canca ve Barrena [22] seferlere tren atama ve dinlenme istasyonlarının belirlenmesi problemini çalışmış ve problem için üç aşamalı bir sezgisel yöntem önermiștir. Demir yolu taşımacıllğında, deniz yolu taşımacılığından farklı olarak ayrıtların araç kapasitesi bulunmaktadır ve bu durum, Canca ve Barrena [22] ele alındığı gibi dinlenme istasyonlarının belirlenmesi ihtiyacını ortaya çıkarmaktadır.

Literatürde deniz yolu tașımacılığında ayrıt rotalama problemini ele alan çalışmalar $[5,16]$ genellikle yük taşımacılığı uygulama alanında yer almaktadır. Bu çalışmalar ile bu çalışmada ele alınan problem arasındaki temel farklılıklar şu şekilde sıralanabilir. Öncelikle, yük taşımacılı̆̆ındaki taleplerde (seferlerde) zaman pencereleri daha esnek iken, tarifeye dayalı yolcu taşımacılığında katı zaman pencereleri bulunur [5]. Ek olarak, yük taşımacılığı uzun mesafe taşımacılık kapsamına girerken [5], bu çalışmada ele alınan problem kısa mesafe taşımacılık kapsamına girmektedir ve bu yapısal farklılık durum çözüm yaklaşımını etkilemektedir. Karapetyan ve Punnen [16] uzun mesafe deniz yolu yolcu taşımacılığında karşılaşılan vapur çizelgeleme problemini ele aldıkları çalışmalarında, vapurlara ait değişken maliyetleri ve müşteri memnuniyetsizliğini en küçüklemeyi hedefleyen bir tam sayılı programlama modeli geliştirmişlerdir. Problemde, kısa süreli planlama çevreni için yolcu transferleri, ekip çizelgeleme ve yolcular için yükleme-boşaltma zamanları dikkate alınmıştır. Çalışmamızdaki probleme benzer şekilde; talepler başlangıç ve bitiş iskeleleri, başlangıç zamanı ve talep miktarı olarak ifade edilmiştir. Çalışmamızdan farklı olarak, problemin uygulama alanı (uzun mesafe yolcu taşımacılı̆̆ı transferi de problem kapsamında modellenmiștir. Geliştirilen matematiksel model ile 3-4 vapur, 7 iskele ve 20 saatlik planlama çevrenini içeren problem örnekleri için kabul edilebilir kalitede sonuçlar elde edilmiştir. Çalışmamızda ise, problem boyutunun büyüklüğü nedeniyle matematiksel model ile kabul edilebilir sürede kabul edilebilir kalitede çözüm elde etmek mümkün olamamaktadır.

Özetle; çalışmamızda, literatürdeki diğer kapasiteli ayrıt rotalama çalışmalarından farklı olarak, araçların (vapurların) depoya dönme zorunluluğunun bulunmadığı, heterojen araç filosu (farklı tiplerde ve kapasitelerde vapurlar) içeren, katı zaman pencerelerine sahip taleplerin (tarifeleri belli, farklı kapasite ihtiyacına sahip seferlerin) bulunduğu, talep-araç (sefer-vapur) kısıtları, dügüm-araç (iskele-vapur) kapasite kısıtları, araç tipi-düğüm (vapur tipi-iskele) kısıtları içeren ve yakıt tüketimi ile dış kaynak kullanımı maliyetlerinden oluşan toplam maliyeti en küçüklemeyi hedefleyen ayrıt rotalama problemi ele alınmıştır. Çalışma kapsamında, öncelikle bir matematiksel model geliştirilmiştir. Matematiksel modelin gerçek boyutlu problem örnekleri için yetersiz kalması nedeniyle, tabu arama yöntemine dayalı bir sezgisel algoritma geliştirilmiştir.

\section{Problem Tanımı}

$\mathrm{Bu}$ bölümde problemin biçimsel tanımı yapılacaktır. Planlama çevrenindeki zaman dilimleri $T$ kümesini ile ifade edilmektedir. Gün içerisinde seferlerin yapıldığı saatler ve sefer sürelerinin tamamı 5 dakikanın katları olarak ifade edilebileceğinden çalışma günü 5 dakikalık dilimlere bölünmüştür. Gün içerisinde seferler 225 zaman dilimi içerisinde yapılıyor olmasına rağmen (05:50 - 00:35 arası), her günün ilk zaman dilimi vapurların gece boyu dinlenmesini ve gün başlangıcını ifade etmek adına 315 dakikaya karşılık gelmektedir. Zaman dilimi $t \in$ $T$ 'nin kaç dakikaya karşılılık geldiği bilgisi $\delta_{t}$ ile ifade edilmektedir.

Firmanın sahip olduğu farklı vapur tipleri $G$ kümesi, filodaki tüm vapurlar ise $F$ kümesi ile ifade edilmektedir. Her bir vapur $f \in F$ için; $\alpha_{f g}$ 0-1 ikili parametresi, $f$ vapurunun $g \in G$ tipinde olup olmadığını belirtmektedir. Vapur $f \in F$ için; yakıt tüketimi maliyeti (TL/mil) $c_{f}^{I}$, yolcu kapasitesi ise $k_{f}$ ile tanımlanmaktadır. Herhangi bir vapur dinlenmeye başlarsa en az $\Delta^{I}$ dakika dinlenmek zorundadır. Bir vapur aynı gün içindeki dinlenmelerinin birinde en az $\Delta^{I I}$ dakika kesintisiz dinlenmelidir. Herhangi bir vapur 
günlük toplamda en az $\Delta^{I I I}$ dakika dinlenmelidir. Herhangi bir vapur en fazla $\Delta^{I V}$ dakika aralıksız çalışabilir.

$P$ kümesi iskeleleri ifade etmektedir. İskele $p \in$ $P$ için; $\beta_{p}$ 0-1 ikili parametresi, $p$ iskelesi tek yüzlü ise 1 , üç yüzlü 0 değerini alır. İskele $p \in P$ için; $\gamma_{p}$ 0-1 ikili parametresi, $p$ iskelesi dinlenme iskelesi (sefer saatlerinde dinleme yapılabilir) ise 1, çalışma iskelesi (sefer saatlerinde dinlenme yapılamaz) ise 0 değerini alır. İskele $p \in P$ için; $\eta_{p t} 0-1$ ikili parametresi, $t \in T$ zaman diliminde seferler devam ediyorsa 1 , diğer durumlarda 0 değerini alır. İskele $p \in P$ ve vapur tipi $g \in G$ için; $o_{p g}$ parametresi $p$ iskelesine $g \in$ $G$ vapur tipinden bağlanabilecek en fazla vapur sayısını verir. Her bir vapur $f \in F$ ve iskele $p \in$ $P$ için; $i_{f p}$ 0-1 ikili parametresi, $f$ vapuru planlama çevreninin bașında $p$ iskelesinde ise 1 değilse 0 değerini alır.

$H$ kümesi hatları, $R$ kümesi ise bu hatlar üzerindeki seferleri ifade etmektedir. $R^{\prime}$ kümesi, $R$ kümesinde yer alan seferlerin yanında iskeleler arasında gerçekleştirilebilecek tüm boş seferleri içerir. Her $r \in R^{\prime}$ seferi için $d_{r}$ seyahat mesafesini (mil), $t_{r}$ ise seyahat süresini (dk.) tanımlanmaktadır. Herhangi bir vapurun çalıșabileceği maksimum hat sayısı $\pi$ ile ifade edilmektedir. Her bir vapur tipi $g \in G$ ve hat $h \in$ $H$ için; $\xi_{g h} 0-1$ ikili parametresi, $g$ vapur tipinden bir vapur $h \in H$ hattından bir sefere atanabiliyorsa 1 , diğer durumda 0 değerini alır. Her bir sefer $r \in R$ ve hat $h \in H$ için; $\theta_{r h} 0$-1 ikili parametresi, $r$ seferinin hangi hat üzerinde olduğunu belirtir. Her bir sefer $r \in R^{\prime}$ için; $s_{r p} \in$ $P$ parametresi $r$ seferinin kalkış iskelesini, $f_{r p} \in$ $P$ parametresi $r$ seferinin varıș iskelesini, $b_{r} \in T$ parametresi $r$ seferinin kalkış zamanını, $e_{r} \in T$ parametresi ise $r$ seferinin varış zamanını belirtir. Dolu sefer tanımları başlangıç ve bitiş iskelelerini içermekte ve ara iskeleler göz ardı edilmektedir. $\mathrm{Bu}$ yöntemle problem boyutu düşürülebilmektedir. Örneğin, İstanbul Şehir Hatları için bu yöntem ile sistemdeki iskele sayısı 38'den 23'e düşmektedir. Seferlerde ara iskelelerde bekleme yapılmaması ve tarifeler hazırlanırken ara iskelelerinin kapasite kısıtlarının firma tarafından gözetilmekte olması da bu yöntemi desteklemektedir. Seferler için ara iskeleler ihmal edilirken tüm iskelelerde binen ve inen yolcuların sayısı dikkate alınarak ve sefer boyunca vapurdaki maksimum yolcu sayısı kullanılarak seferlerin yolcu sayıları tahmin edilmektedir. Her bir $r \in R$ seferi için, $l_{r}$, $r$ seferinin tahmini yolcu sayısını verir. Her bir sefer $r \in R$ için, dıs kaynak kullanımı maliyeti (TL) $c_{r}^{I I}$ ile tanımlanmaktadır.

\section{Matematiksel Model}

Ele alınan problemin çözümü için öncelikle tam sayılı programlama modeli geliştirilmiştir.

\section{Kümeler:}

$G$ : Vapur tipleri kümesi

$F$ : Vapurlar kümesi

$P$ : İskeleler kümesi

$H$ : Hatlar kümesi

$R$ : Tarifeli seferler kümesi

$R^{\prime}$ : Boş seferleri de içeren seferler kümesi

$T$ : Planlama çevrenindeki zaman dilimleri kümesi

\section{Parametreler:}

$\delta_{t} \quad:$ Zaman dilimi $t \in T^{\prime}$ nin karşıllılı geldiği dakika cinsinden süre

$\alpha_{f g}: f \in F$ vapuru $g \in G$ tipinde ise 1 , diğer durumlarda 0

$c_{f}^{I} \quad: f \in F$ vapurunun yakıt tüketimi maliyeti (TL/mil)

$k_{f}: f \in F$ vapurunun yolcu kapasitesi

$\Delta^{I} \quad$ : Vapurlar için en mümkün olan en kısa dinlenme suresi

$\Delta^{I I}$ : Vapurların gün içindeki dinlenmelerinden en az birinde minimum dinlenmesi gereken süre

$\Delta^{I I I}$ : Vapurların gün içinde toplamda en az dinlenmeleri gereken süre

$\Delta^{I V}$ : Vapurların kesintisiz maksimum çalışabileceği süre

$\beta_{p}: p \in P$ iskelesi tek yüzlü ise 1 , üç yüzlü 0 değerini alır

$\gamma_{p}: p \in P$ dinlenme iskelesi ise 1 , çalışma iskelesi ise 0 değerini alır

$\eta_{p t}: p \in P$ iskelesinde $t \in T$ zaman diliminde seferler devam ediyorsa 1 , diğer durumlarda 0

$o_{p g}: p \in P$ iskelesine $g \in G$ vapur tipinden bağlanabilecek en fazla vapur sayısı

$i_{f p}: f \in F$ vapuru planlama çevreninin başında $p \in P$ iskelesinde ise 1 , değilse 0 değerini alır

$\pi \quad$ : Herhangi bir vapurun çalıșabileceği maksimum hat sayısı

$\theta_{r h}: r \in R$ seferi $h \in H$ hattında ise 1 , değilse 0 değerini alır

$l_{r} \quad: r \in R$ seferinin tahmini yolcu sayısı

$c_{r}^{I I}: r \in R$ seferi için dıs kaynak kullanımı maliyeti (TL)

$s_{r p}: r \in R^{\prime}$ seferi, $p \in P$ iskelesinden kalkıyor ise 1 , diğer durumlarda 0 
$f_{r p}: r \in R^{\prime}$ seferi, $p \in P$ iskelesine variyor ise 1 , diğer durumlarda 0

$b_{r} \quad: r \in R^{\prime}$ seferinin kalkış zamanı

$e_{r} \quad: r \in R^{\prime}$ seferinin varış zamanı

$d_{r}: r \in R^{\prime}$ seferinin seyahat mesafesi (mil)

$t_{r} \quad: r \in R^{\prime}$ seferinin seyahat süresi (dk)

$\xi_{g h}: g \in G$ vapur tipinden bir vapur $h \in H$ hattından bir sefere atanabiliyorsa 1 , diğer durumda 0

$M$ : yeterince büyük bir sayı

\section{Karar Değişkenleri:}

$X_{f r}: f \in F$ vapuru $r \in R^{\prime}$ seferine atanmışsa 1 , diğer durumlarda 0 değerini alır

$S_{r} \quad: r \in R$ seferi kiralık vapurla gerçekleştiriliyorsa 1, diğer durumlarda 0 değerini alır

$Y_{f p t}: f \in F$ vapuru $t \in T$ zaman diliminde $p \in P$ iskelesindeyse 1 , diğer durumlarda 0 değerini alır

$V_{f p t}: f \in F$ vapuru $t \in T$ zaman diliminde $p \in P$ iskelesinde dinleniyorsa 1 , diğer durumlarda 0 değerini alır

$U_{f p t}: f \in F$ vapuru $t \in T$ zaman diliminde $p \in P$ iskelesinde dinlenmeye başladıysa 1 , diğer durumlarda 0 değerini alır

$I_{f h} \quad: f \in F$ vapuru $h \in H$ hattındaki bir seferde çalışıyorsa 1 , diğer durumlarda 0 değerini alır

\section{Amaç Fonksiyonu:}

Matematiksel modelde kullanılan amaç fonksiyonu (2), vapurların gerçekleștirdikleri boş ve dolu seferlerdeki toplam yakıt tüketimi maliyetlerinden $\left(C^{Y}\right)$ ve diş kaynak kullanımı maliyetlerinden $\left(C^{S}\right)$ oluşan toplam maliyetleri en küçüklemeyi hedeflemektedir.

En küçükle

$$
C^{Y}+C^{S}
$$

\section{Kisitlar:}

$$
\begin{aligned}
& C^{Y}=\sum_{f \in F} \sum_{r \in R^{\prime}} X_{f r} d_{r} c_{f}^{I} \\
& C^{S}=\sum_{r \in R} S_{r} c_{r}^{I I} \\
& \sum_{f \in F} X_{f r}+S_{r}=1, r \in R \\
& X_{f r} l_{r} \leq k_{f}, f \epsilon F, r \in R, \\
& Y_{f, s_{r}, b_{r}} \geq X_{f r}, f \epsilon F, r \in R^{\prime} \\
& Y_{f, f_{r}, e_{r}} \geq X_{f r}, f \in F, r \in R^{\prime} \\
& X_{f r} \theta_{r h} \leq I_{f h}, f \epsilon F, r \in R, h \in H
\end{aligned}
$$

$$
\begin{aligned}
& \sum_{h \in H} I_{f h} \leq \pi, f \epsilon F \\
& Y_{f, p, 0} \leq i_{f p}, f \epsilon F, i \epsilon P \\
& Y_{f p t} \leq Y_{f, p, t+1}+\sum_{r \in R: b_{r}=t+1 \& s_{r}=p} X_{f r}, \\
& f \in F, p \in P, t \in T \\
& V_{f p t} \leq Y_{f p t}, f \epsilon F, p \in P, t \in T \\
& \left(1-X_{f r}\right) M \geq V_{f p t} \text {, } \\
& f \in F, p \in P, r \in R, t \in T: b_{r} \leq t \leq e_{r} \\
& \sum_{p \in P} Y_{f p t} \leq 1, f \in F, t \in T \\
& \sum_{f \in F} V_{f p g} \alpha_{f g} \leq o_{i g}, p \in P, g \in G, t \in T \\
& \sum_{f \in F} V_{f p t} \eta_{p t} \leq M\left(\gamma_{p}-1\right), \quad p \in P, t \in T \\
& V_{f, p, t+1}-V_{f p t} \leq U_{f, p, t+1}, \\
& f \epsilon F, p \in P, t \in T \\
& \Delta^{I} U_{f p t} \leq \sum_{t^{\prime} \in T: t \leq t^{\prime} \leq \frac{\Delta^{I}}{5}} V_{f p t} \delta_{t},
\end{aligned}
$$$$
f \epsilon F, p \in P, t \epsilon T
$$$$
\begin{aligned}
& \sum_{p \in P} \sum_{t=224(k-1)+2}^{224(k-1)+11} V_{f p t} \delta_{t} \\
& +\sum_{p \in P} \sum_{t=224 k-9}^{224 k} V_{f p t} \delta_{t} \geq \Delta^{I I}, f \in F
\end{aligned}
$$$$
\sum_{p \in P} \sum_{t=224(k-1)+1}^{224 k} V_{f p t} \delta_{t} \geq \Delta^{I I I},
$$$$
f \epsilon F, k=1, \ldots, T / 224
$$$$
\text { (1) } \sum_{p \in P} V_{f, p,(224(k-1)+1)}=1 \text {, }
$$$$
f \epsilon F, k=1, \ldots, T / 224
$$$$
\sum_{p \in P} \sum_{t \prime=t}^{t+96} V_{f p t} \geq 1 \text {, }
$$$$
f \in F, t \in T: t \neq 1(\bmod 224)
$$$$
X_{f r} \theta_{r h} \leq \xi_{g h} \alpha_{f g} \text {, }
$$$$
f \in F, r \in R, h \in H, g \in G
$$$$
\text { (5) } \sum_{f \in F} \sum_{g \in G: 1 \leq g \leq 4} V_{f p t} \alpha_{f g} \leq o_{p 1}, p \in P, t \in T
$$ 


$$
\begin{aligned}
& V_{f p t} \alpha_{f g}+V_{f p t} \alpha_{f g^{\prime}} \leq 1+\left(1-\beta_{p}\right) M, \\
& f \in F, p \in P, t \in T \text {, } \\
& g, g^{\prime} \in G: 1 \leq g \leq 4 \& 5 \leq g^{\prime} \leq 6 \\
& \sum_{f \in F} V_{f p t} \leq o_{p 5}\left(1-\beta_{p}\right)+\beta_{p} M \text {, } \\
& p \in P, t \in T \\
& 2 \sum_{f \in F} \sum_{g \in G: 1 \leq g \leq 4} V_{f p t} \alpha_{f g} \\
& +\sum_{\substack{f \in F \\
\leq o_{p 5},}} \sum_{g \in G: 5 \leq g \leq 6} V_{f p t} \alpha_{f g} \\
& p \in \mathcal{P}: p=\text { Üsküdar, } t \in T \\
& V_{f p t} \alpha_{f g}+V_{f p t} \alpha_{f g^{\prime}} \leq 1 \text {, } \\
& f \in F, p \in P=\text { Eminönü, } t \in T \text {, }
\end{aligned}
$$

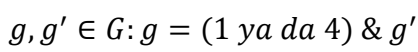

$$
\begin{aligned}
& =(2 \text { ya da } 3) \\
& X_{f r}, S_{r}, Y_{f p t}, U_{f p t}, I_{f h} \in\{0,1\} \text {, } \\
& f \in F, r \in R, p \in P, t \in T, h \in H
\end{aligned}
$$

Kısıt (2), vapurların gerçekleştirdikleri boş ve dolu seferlerdeki toplam yakıt tüketimi maliyetlerini hesaplar. Kısıt (3), dış kaynak kullanımı maliyetlerini hesaplar. Kısıt (4), her seferin filodan veya kiralı bir vapur ile gerçekleştirilmesini sağlar. Kısıt (5), bir sefere atanan vapurun yolcu kapasitesinin en az seferin yolcu sayısı kadar olmasını sağlar. Kısıt (6) bir sefere başlayan vapurun bu seferin başlangıç iskelesinde olmasını sağlar. Kısıt (7) ise, bir sefere başlayan vapurun bu seferin bitiș zamanında seferin bitiş iskelesinde olmasını sağlar. Kısıt (8) ile bir sefere atanan vapurun o seferin ait olduğu hatta çalışması sağlanır. Kısıt (9) bir vapurun çalışabileceği farklı hat sayısını $\pi$ ile sınırlar. Kısıt (10) ile bir vapurun planlama çevreninin ilk zaman diliminde verilen konumda olmasını sağlar. Kısıt (11) ile $t$ zaman diliminde bir iskelede olan ve $(t+1)$ 'de bir sefere başlamayan bir vapurun $(t+1)^{\prime}$ de de o iskelede olması sağlanır. Kısıt (12) ile bir vapur bir iskelede dinleniyorsa o iskeleye bağlı olması sağlanır. Kısıt (13) ile bir zaman diliminde boş veya dolu bir sefere başlayan bir vapur, sefer süresince dinleniyor olamaz. Kisit (14) ile bir vapur herhangi bir zaman diliminde en fazla bir iskelede bulunabilir. Kisıt (15) ile bir iskelede dinlenen bir vapur tipine ait vapur sayısının, en fazla, o iskelede o vapur tipinden dinlenebilecek vapur sayısı kadar olması sağlanır. Kısıt (16), sefer yapılan iskelelerde seferlerin devam ettiği zaman dilimlerinde hiçbir vapurun dinlenmemesini sağlar. Kısıt (17) ile $t$ zaman diliminde dinlenmeyen ancak $(t+1)$ zaman diliminde dinlenen bir vapurun $(t+1)$ zaman diliminde dinlenmeye başlaması sağlanır. Kısıt (18) ile gün içinde dinlenmeye başlayan bir vapurun en az $\Delta^{I}$ dakika (İstanbul Şehir Hatları için 2 saat yani 24 zaman dilimi) kesintisiz dinlenmesi sağlanır. Kısıt (19) ile her vapurun her gün bir kere en az $\Delta^{I I}$ dakika (İstanbul Şehir Hatları için 6 saat) dinlenmesi koșulu sağlanır. Kisit (20) ve (21) ile her vapurun günde en az $\Delta^{I I I}$ dakika dinlenmesi sağlanır. İstanbul Şehir Hatları için $\Delta^{I I I}, 10$ saate yani gün içerisindeki 315 dakikalık ilk zaman diliminde tüm vapurlar dinlendiği 58 zaman dilimine karşılık gelmektedir. Kısıt (22) ile bir vapurun kesintisiz olarak en fazla $\Delta^{I V}$ dakika (İstanbul Şehir Hatları için 8 saat yani 96 zaman dilimi) çalışması sağlanır. Kısıt (23) ile bir sefere atanan vapur ile o seferin hattının ve vapurun tipinin uyumlu olması sağlanır. İstanbul Şehir Hatları için Haliç Hattındaki seferlere sadece 5. vapur tipindeki vapurlar ve Adalar Hattındaki seferlere sadece 5. veya 6 . vapur tipindeki vapurlar atanması atanmalıdır.

(24) ila (29) arası kısıtlar, İstanbul Şehir Hatları operasyonlarına özgü olarak iskelelere ait vapur tiplerine özel kısıtları tanımlar. Kısıt (24) ile bir iskelede dinlenen 1.-4. gruplara ait vapur sayısı toplamının, en fazla, o iskelede dinlenebilecek 1. gruba ait vapur sayısı kadar olması sağlanır. Kısıt (25) ile bir iskelede dinlenen 5 ve 6 . gruplara ait vapur sayısı toplamının, en fazla, o iskelede dinlenebilecek 5. gruba ait en fazla vapur sayısı kadar olması sağlanır. Kısıt (26) ile tek yüzlü iskelelerde 1.-4. gruplardan herhangi bir vapur ile 5. veya 6. gruplardan bir vapurun aynı anda dinlenmemesi sağlanır. Kısıt (27) ile üç yüzlü iskelelerde, iskelede dinlenecek toplam vapur sayısının, en fazla, o iskelede dinlenebilecek 5 . vapur grubundan vapur sayısı kadar olması sağlanır. Kısıt (28) ile Üsküdar İskelesi'nde 1.-4. gruplardan dinlenen vapur sayısının 2 katı ile 5. ve 6. gruplardan dinlenen vapur sayısı toplamının bu iskelede dinlenebilecek 5. grup vapur sayısını geçmemesi sağlanır. Kısıt (29) ile Eminönü Camlı İskele'de 2. veya 3. gruptan herhangi bir vapur ile 1 . veya 4 . gruptan herhangi bir vapurun aynı anda bağlanmaması sağlanır.

Kısıt (30), karar değişkenleri için 0-1 ikili değișken olma durumunu tanımlar. 
Geliștirilen matematiksel modelin performansı farklı boyutlardaki gerçekçi problem örnekleri üzerinde analiz edilmiștir. Bu analizlere ilișkin sonuçlar Bölüm 6'da paylaşılmaktadır. Yapılan analizlerde, problem örneklerinin boyutu büyüdükçe modelin kabul edilebilir sürede, kabul edilebilir kalitede çözüm üretmediği gözlenmiştir.

\section{Sezgisel Çözüm Yöntemi}

Problemin gerçek boyutlu örnekleri için kısa sürede kaliteli sonuçlar almak amacıyla, çalıșma kapsamında bir sezgisel çözüm yöntemi geliștirilmiştir. Sezgisel yöntem, iki adımdan oluşmaktadır. Birinci adımda, inşa algoritması ile olurlu bir başlangıç çözümü elde edilir. İkinci adımda, elde edilen bu bașlangıç çözümü tabu arama yöntemiyle iyileștirilir. Sezgisel yöntem için notasyon bilgisi Ek A'da verilmiştir.

5.1. Başlangıç çözümünün oluşturulması: İnşa algoritması

Başlangıç çözümü oluşturulması adımında öncelikle seferler, sefer başlangıç saatlerine $\left(b_{r}\right)$ göre, vapurlar ise yakıt tüketimlerine göre $\left(c_{f}^{I}\right)$ göre küçükten büyüğe sıralanır. Seferler bu sıra ile tek tek ele alınır ve her sefer koşulları (seferin yolcu talebi ile atandığı vapurun yolcu kapasitesi uyumu, hat-vapur kisitları uyumu, iskelelerin vapur kapasiteleri, vapurların iskelelere bağlanabilme kısıtları) sağlayan en düşük yakıt tüketimine sahip vapura atanır. Bu koşulların yanı sıra, bir seferin bir vapura atanması sırasında, eğer seferin varıș iskelesi dinlenme iskelesi değilse ve seferin varıș saati o iskelede seferlerin devam ettiği bir zamana denk geliyorsa, seferin varıș saatinde varıș iskelesinden başlayan ve koşulları sağlayan bir sefer vapura atanır. Bu şekilde bir sefer bulunamaması durumunda, vapur en yakın dinlenme iskelesine dinlenmeye gönderilir. Ĕger bir sefer için tüm koșulları sağlayan bir vapur bulunamazsa, sefere diş kaynak ataması yapılır.

5.2. Başlangıç çözümünün iyileștirilmesi: Tabu arama algoritması

Sezgiselin ikinci adımında tabu arama yöntemi ile başlangıç çözümünün iyileştirilmesi hedeflenir. Tabu arama yöntemi, ayrıt rotalama problemlerinin genel sınıfı olan araç rotalama problemlerinin (ARP) birçok varyantına (örn. zaman pencereli ARP [18]) uygulanmış ve büyük boyutlu problem örneklerinde de kaliteli sonuçların türetildiği görülmüştür [19].

Tabu arama yöntemi, yinelemeli (iteratif) bir süreçten oluşur ve her yinelemede (iterasyonda) mevcut çözümden komșuluk hareketleri kullanılarak komşu çözümler elde edilir. Bir yinelemede, tabu koşullarını bozmayan en iyi komșu çözüm (en iyi iyileștirme - best improvement- tekniği ile) bir sonraki yinelemenin mevcut çözümü olur. Tüm yinelemeler boyunca bulunan en iyi çözüm dönülür [20].

Geliştirilen tabu arama algoritmasında aşağıda tanımlanan üç komşuluk hareketi kullanılmaktadır:

(1) Ekle: Mevcut çözümde diş kaynak kullanılarak gerçekleştirilen bir sefer, koşulları sağlayan en uygun vapura atanır,

(2) Çıkart-Ekle: Mevcut çözümde bir vapura atanmış olan bir sefer, o vapurun rotasından çıkartılarak koşulları sağlayan rastgele bir vapura atanir,

(3) Değiştir: Mevcut çözümdeki iki seferin atandığı vapurlar (dış kaynak da dâhil olmak üzere) koşullar izin veriyorsa değiștirilir.

Seferler kümesinin boyutu $|R|$ ve vapurlar kümesinin boyutu $|F|$ ise, Ekle komşuluğun boyutu $O(|R|)$, Çוkart-Ekle komşuluğunun boyutu $O(|R||F|)$, Değiștir komşuluğunun boyutu $O\left(|R|^{2}\right)$, dolayısıyla, tüm komşuluğun boyutu $O\left(|R|^{2}\right)^{\prime}$ dir. Her bir komşuluk hareketi için ayrı bir tabu listesi kullanılarak, son $\vartheta$ yineleme sırasında yapilan bir hareketin önlenmesi sağlanır. Çeşitlendirme (diversifikasyon) stratejisi olarak, yinelemeler boyunca en iyi çözümden daha iyi olmayan çözümlerin bir sonraki yinelemenin mevcut çözümü olarak belirlenmesi izin verilir.

Durma koşulu olarak, en fazla yineleme sayısı $(v)$ veya iyileștirme olmayan en fazla yineleme sayısı $(\rho)$ kullanılır.

\section{Deneysel Çalıșmalar}

\subsection{Problem örneklerinin oluşturulması}

Geliştirilen çözüm yöntemlerinin performanslarını değerlendirmek amacıyla; İstanbul Şehir Hatları tarafından sağlanan bir aylık sefer verileri kullanılarak küçük boyutlu (KB) ve gerçek boyutlu (GB) problem örnekleri oluşturulmuştur. Tüm problem örnekleri için vapur filosuna ve kullanılan iskelelere ilișkin bilgiler, sırasiyla, Tablo 1 ve Tablo 2'de verilmektedir.

Oluşturulan küçük boyutlu (KB) ve gerçek boyutlu problem (GB) örneklerinin problem büyüklüklerine ilişkin Tablo 3'te verilmektedir. 
Tablo 1. İstanbul Sehir Hatları A.Ş.'deki vapur filosuna ilișkin bilgiler

\begin{tabular}{cccc}
\hline $\begin{array}{c}\text { Vapur Tipi } \\
(G)\end{array}$ & $\begin{array}{c}\text { Vapur } \\
\text { Sayısı }\end{array}$ & $\begin{array}{c}\text { Yolcu Kapasitesi } \\
\left(k_{f}\right)\end{array}$ & $\begin{array}{c}\text { Yanaşma } \\
\text { Şekli }\end{array}$ \\
\hline A & 5 & 1800 & Yan \\
B & 3 & 2100 & Yan \\
C & 2 & 2100 & Yan \\
D & 11 & 1500 & Yan \\
E & 3 & 600 & Dik \\
F & 4 & 700 & Dik \\
\hline
\end{tabular}

Tablo 2. İstanbul Șehir Hatları A.Ș. tarafından kullanılan iskelelere ilișkin bilgiler

\begin{tabular}{ccc}
\hline İskele Sınıfı & İskele Tipi & İskele Sayısı \\
\hline Amacına & Dinlenme & 6 \\
\cline { 2 - 3 } Göre & Çalışma & 17 \\
\hline $\begin{array}{c}\text { Yapısına } \\
\text { Göre }\end{array}$ & Üç Yüzlü & 4 \\
\cline { 2 - 3 } & Tek Yüzlü & 19
\end{tabular}

Küçük boyutlu problem örnekleri (KB-1-40, KB1-60, KB-2-40) bir veya iki hattaki bir günlük seferleri kapsayacak şekilde oluşturulmuş ve matematiksel model ile sezgisel yöntemin performanslarının karşılaştırılması amacıyla kullanılmıștır. Performans karşılaștırmasına ilişkin sonuçlar Bölüm 6.2.1'de verilmektedir.

Tablo 3. Problem örnekleri için problem büyüklüklerine ilișkin bilgiler

\begin{tabular}{ccccccc}
\hline Örnek & $\begin{array}{c}\text { Vapur tipi } \\
\text { Kodu }\end{array}$ & $\begin{array}{c}\text { Vayur } \\
\text { sayıs }\end{array}$ & $\begin{array}{c}\text { Iskele } \\
\text { sayısı }\end{array}$ & $\begin{array}{c}\text { sayıs } \\
\text { say }\end{array}$ & $\begin{array}{c}\text { Sayıs } \\
\text { sefer }\end{array}$ & Gün \\
& $|G|$ & $|F|$ & $|P|$ & $|H|$ & $|R|$ & \\
\hline KB-1-40 & 3 & 3 & 3 & 1 & 40 & 1 \\
KB-1-60 & 3 & 4 & 3 & 1 & 60 & 1 \\
KB-2-40 & 3 & 3 & 4 & 2 & 40 & 1 \\
GB-326 & 6 & 28 & 23 & 9 & 326 & 1 \\
GB-363 & 6 & 28 & 23 & 9 & 363 & 1 \\
GB-371 & 6 & 28 & 23 & 9 & 371 & 1 \\
GB-373 & 6 & 28 & 23 & 9 & 373 & 1 \\
GB-5092-1 & 6 & 28 & 23 & 9 & 5092 & 14 \\
GB-5092-2 & 6 & 28 & 23 & 9 & 5092 & 14 \\
GB-5092-3 & 6 & 28 & 23 & 9 & 5092 & 14 \\
\hline
\end{tabular}

Sefer sayısı 300 ila 400 arası olan gerçek boyutlu örnekler (GB-371, GB-373, GB-363, GB-326), sırasıyla Perșembe, Cuma, Cumartesi ve Pazar günlerindeki tüm seferleri kapsayacak şekilde oluşturulmuştur. İstanbul Şehir Hatları için Pazartesi-Perşembe günlerindeki seferler farklılık göstermemektedir. Son olarak, GB-
5092-1, GB-5092-2, GB-5092-3 kodlu örnekler, İstanbul Sehir Hatları tarafından sağlanan bir aylık sefer verilerinin iki haftalık olarak gruplandırılması ile ve ilgili haftalardaki tüm seferleri kapsayacak şekilde oluşturulmuştur. Önerilen sezgisel yöntemin gerçek boyutlu problem örnekleri için sonuçları Bölüm 6.2.2'de verilmektedir.

Dıș kaynak maliyeti tüm seferler için $c_{r}^{I I}=10.000$ TL olarak alınmıştır. Vapurların yakıt tüketim maliyetleri $\left(c_{f}^{I}\right)$ 14,59 TL/mil ile 40,5 $\mathrm{TL} / \mathrm{mil}$ aralığında değișmektedir. Vapurların kapasiteleri $\left(k_{f}\right) 600$ yolcu ile 1800 yolcu aralığında değişmektedir. Seferlerin yolcu talepleri ise, 15 ile 1200 arasında değișmektedir.

\subsection{Deneysel çalışmalar}

Oluşturulan problem örneklerinin çözümü için, geliştirilen yöntemler Intel core i9, $2.9 \mathrm{GHz}$, 64GB, 64 bit özelliklerindeki bir bilgisayarda, CPLEX OPL 12.4 çözücüsü kullanılarak \%1 optimalite aralığı toleransı ile çözdürülmüștür. Geliştirilen sezgisel yöntem, C\# programlama dilinde kodlanmıştır. Yapılanan ön analizler sonucunda, sezgisel yöntemin $(v, \rho)$ parametrelerinin değerleri deneysel çalışmalarda $(100,10)$ olarak alınmıştır.

Her problem örneği için mevcut duruma ilişkin maliyet bilgileri de raporlanmıştır.

6.2.1. Matematiksel model ve sezgisel yöntemin karşılaştırmalı sonuçları

Küçük boyutlu problem örnekleri için, matematiksel modelin ve sezgisel yöntemin çalışma süreleri ve ürettiği sonuçların maliyetleri ile mevcut durumdaki maliyetler Tablo 4'te verilmektedir. Bu gruptaki tüm örnekler için mevcut durumda ve önerilen yöntemlerin ürettiği sonuçlarda dış kaynak kullanımı bulunmamaktadır.

Tablo 4'te görüldüğü gibi; küçük boyutlu problem örneklerinde dahi, sefer sayısı arttıkça matematiksel modelin çalışma süresi çok artmaktadır. Diğer taraftan, sezgisel yöntem küçük boyutlu problem örnekleri için, kısa sürede optimal veya optimale yakın sonuçlar üretmektedir.

\subsubsection{Gerçek problem örnekleri için sezgisel sonuçları}

Gerçek boyutlu problem örnekleri için sezgisel yöntemin ürettiği sonuçlar ve mevcut durumdaki maliyetler Tablo 5'te verilmektedir. Tablo 5'te, her bir problem örneği için; mevcut durumdaki maliyetler ve sezgisel yöntemin yakıt 
ve dıs kaynak kullanım maliyetlerine ilișkin sonuçlar ile çalıșma süreleri verilmektedir. Bu gruptaki tüm örnekler için mevcut durumda ve önerilen yöntemlerin ürettiği sonuçlarda dış kaynak kullanımı bulunmamaktadır.

İki haftalık planlama sürecine sahip gerçek boyutlu problem örnekleri (GB-5092-1, GB5092-2, GB-5092-3) için, planlama çevreninin ilk gününden başlayarak ileriye doğru her bir gün için birer günlük olacak şekilde ve vapurların bașlangıç iskeleleri önceki günün son iskelesi olacak şekilde sezgisel algoritma çalıștırılmıș ve sonuçlar elde edilmiștir.

Tablo 5'te görüldüğü gibi, sezgisel yöntem gerçek boyutlu problem örnekleri için mevcut atamalara kıyasla önemli oranlarda iyileştirme sağlamaktadır. Sezgiselin çözüm süresi ise, iki haftalık problem örnekleri için dahi kabul edilebilir düzeydedir.

Tablo 4. Küçük boyutlu problem örneklerinde mevcut durumun ve önerilen yöntemlerin karşılaştırılması

\begin{tabular}{|c|c|c|c|c|c|c|c|}
\hline \multirow{3}{*}{ Örnek } & \multicolumn{2}{|c|}{ Çalışma Süresi (dk.) } & \multicolumn{5}{|c|}{ Yakıt Maliyeti (TL) } \\
\hline & \multirow[t]{2}{*}{ Model } & \multirow[t]{2}{*}{ Sezgisel } & \multirow[t]{2}{*}{ Mevcut } & \multirow[t]{2}{*}{ Model } & \multirow[t]{2}{*}{ Sezgisel } & \multicolumn{2}{|c|}{ İyileştirme (\%) } \\
\hline & & & & & & Model & Sezgisel \\
\hline KB-1-40 & 472 & 0,01 & 3.874 & 3.807 & 3.807 & 1,7 & 1,7 \\
\hline KB-1-60 & 1471 & 0,05 & 5.744 & 5.418 & 5.418 & 5,7 & 5,7 \\
\hline KB-2-40 & 445 & 0,04 & 3.380 & 3.275 & 3.281 & 3,1 & 2,9 \\
\hline
\end{tabular}

Tablo 5. Gerçek boyutlu problem örneklerinde mevcut durumun ve sezgisel yöntemin karşılaştırılması

\begin{tabular}{|c|c|c|c|c|}
\hline \multirow[b]{2}{*}{ Örnek } & \multicolumn{3}{|c|}{ Toplam Maliyet (TL) } & \multirow{2}{*}{$\begin{array}{l}\text { Sezgisel Çalışma Süresi } \\
\text { (dk.) }\end{array}$} \\
\hline & Mevcut & Sezgisel & İyileştirme (\%) & \\
\hline GB-326 & 36.318 & 25.411 & 30,0 & 18,42 \\
\hline GB-363 & 37.323 & 28.902 & 22,6 & 16,19 \\
\hline GB-371 & 38.966 & 27.376 & 29,7 & 29,43 \\
\hline GB-373 & 39.186 & 26.991 & 31,1 & 66,76 \\
\hline GB-5092-1 & 537.382 & 396.616 & 26,2 & 304,66 \\
\hline GB-5092-2 & 536.945 & 403.965 & 24,7 & 385,45 \\
\hline GB-5092-3 & 538.312 & 401.112 & 25,4 & 312,51 \\
\hline
\end{tabular}

\section{Sonuç ve Değerlendirme}

Bu çalıșmada, gerçek hayatta İstanbul Șehir Hatları A.Ş.'nin periyodik olarak karşılaștığı, şehir içi deniz yolu toplu taşımacılığında tarifelerde saatleri belirlenen seferlere vapur atama ve rotalama problemi ele alınmıștır. Vapurların atanması ve rotalanmasinda; seferler-yolcu talepleri, hat-vapur kisitlamaları, vapur-yolcu kapasiteleri, iskele-vapur kapasiteleri, vapurların iskelelere bağlanabilme kısıtları dikkate alınmıștır. Ek olarak, personellerin günlük çalışma saatini belirleyen kanuni düzenlemelerin vapurların çalışma saatlerine etkisi dikkate alınmıştır. Amaç, yakıt tüketimi ve dış kaynak kullanımı maliyetlerinden oluşan toplam maliyetleri en küçüklenmektir.
Problem; zaman penceresi, araç-durak uyumu ve durakların araç kapasite kısıtlarını aynı anda ele alması nedeniyle literatürdeki diğer kapasite kısıtlı ayrıt rotalama problemlerinden farklılık göstermektedir.

$\mathrm{Bu}$ çalışmada, öncelikle problem için bir matematiksel model geliştirilmiştir. Gerçek boyutlu problem örnekleri için matematiksel modelin yetersiz kalması nedeniyle tabu arama yöntemine dayalı bir sezgisel yöntem geliştirilmiştir. Geliştirilen yöntemin etkinliği gerçekçi veri kümeleri üzerinde test edilmiştir.

Gerçekçi veriler için, sezgisel yöntem ile hızlı ve mevcut durumdaki maliyetlere klyasla önemli düzeyde iyileștirmeler sağlayan kaliteli sonuçlar elde edilmiștir. 
Geliștirilen sezgisel yöntem ile vapur atamalarının daha sistematik ve kısa sürede, maliyeti azaltacak şekilde ve uyulması gereken tüm kural ve kısıtlara uyularak yapılabilmesi sağlanacaktır. Ek olarak; sezgisel ile vapur atamalarının belirli hat ve vapurları sınırlandırarak yapılabilmesi, arıza veya sefer iptali gibi ani değişikliklerin yaşandığı durumlarda sezgisel ile hızlı bir şekilde yeni sonuçlar elde edilebilmesi, firmanın dinamikliğine katkı sağlayacaktır. Bunların yanı sıra; sezgisel yöntemin, vapur alınması veya yeni bir seferin açılması gibi stratejik kararlar öncesinde veya şu an kiralık olarak verilen ve proje kapsamı dışında tutulan hat ve seferlerin Şehir Hatları tarafından düzenlenmesi durumunda oluşacak maliyet değişimlerinin analizinde kullanılması ile önemli karar desteği kazanımlarının elde edeceği öngörülmektedir.

\section{Teşekkür}

Çalışmanın çeşitli aşamalarındaki katkılarından dolayı Bekir Şahin, Uğur Tahsin Şenel, Alperen Avşar, Efecan Erkilet ve Şerik Kavlak’a teșekkür ederiz.

\section{Kaynakça}

[1] Tiwari, G. 2006. Urban Passenger Transport: Framework for an Optimal Modal Mix, INRM Policy Brief Series, No: 1, Asian Development Bank, New Delhi.

[2] http://www.udhb.gov.tr/images/kurumsal/3kbit.p df (Erișim Tarihi: 19/06/2018)

[3] Kepir, B., Koçyiğit, Ç., Koyuncu, I., Özer, M.B., Yetis Kara, B., Gürbüz, M.A. 2016. Flight-Scheduling Optimization and Automation for AnadoluJet Interfaces, Cilt. 46(4), s. 315-325. DOI: 10.1287/inte.2016.0853

[4] Sniezek, J. 2001. The capacitated arc routing problem with vehicle/site dependencies: An application of arc routing and partitioning, University of Maryland, $\mathrm{PhD}$ thesis.

[5] Yan, S., Chen, C.H., Chen, H.Y., Lou, T.C. 2007. Optimal scheduling models for ferry compaies under alliances, Journal of Marine Science and Technology, Cilt. 15, s. 53-66.

[6] Huisman, D., Kroon, L.G., Lentink, R.M., Vromans, M.J.C.M. 2005. Operations Research in passenger railway transportation, Statistica Neerlandica, Cilt. $59(4)$, s. $467-497$. DOI: $10.1111 / \mathrm{j} .1467$ 9574.2005.00303.x

[7] Eiselt, H.A., Gendreau, M., Laporte, G. 1995b. Arc Routing Problems, Part 1: The Chinese Postman Problem, Operations Research, Cilt. 43(2), s. 231242. DOI: $10.1287 /$ opre.43.2.231

[8] Eiselt, H. A., Gendreau, M., Laporte, G. 1995b. Arc Routing Problems, Part 2: The Rural Postman Problem, Operations Research, Cilt. 43(3), s. 399414. DOI: $10.1287 /$ opre.43.3.399

[9] Eglese, R.W., Murdock, H. 1991. Routing Road Sweepers in a Rural Area, The Journal of the Operational Research Society, Cilt. 42, s. 281-288. DOI: $10.2307 / 2583381$

[10] Eglese, R.W., Li, L.Y.O. 1992. Efficient Routing for Winter Gritting, The Journal of the Operational Research Society, Cilt. 43, s. 1031-1034. DOI: 10.1057/palgrave.jors.0431102

[11] Bouliane, J., Laporte, G. 1992. Locating Postal Relay Boxes Using a Set Covering Algorithm, Am. J. Math And Mgmt. Sci., Cilt. 12, s. 65-74. DOI: 10.1016/j.cor.2010.04.010

[12] Wunderlich, J., Collette, M., Levy, L., Bodin, L.D. 1992. Scheduling Meter Readers for Southern California

Gas Company, Interfaces Cilt. 22(3), s. 22-30. DOI: 10.1287/inte.22.3.22

[13] Usberti, F.L., Franc, P. M., Frank, A.L.M. 2011. The Open Capacitated Arc Routing Problem, Computers \& Operations Research, Cilt. 38(11), s. 1543-1555. DOI: 10.1016/j.cor.2011.01.012

[14] Ulusoy, G. 1985. The fleet size and mix problem for capacitated arc routing, European Journal of Operational Research, Cilt. 22, s. 329-337. DOI: 10.1016/0377-2217(85)90252-8

[15] Cattrysse, D., Muyldermans, L., Van Oudheusden, D. 2003. District design for arc routing applications, Journal of the Operational Research Society, Cilt. 54, S. 1209-1221. DOI: $10.1057 /$ palgrave.jors.2601626

[16] Karapetyan, D., Punnen A.P. 2013. A reduced integer programming model for the ferry scheduling problem, Public Transport, Cilt. 4(3), s. 151-163. DOI: 10.1007/s12469-012-0058-0

[17] Orhan, I., Kapanoğlu, M., Karakoç H. 2010. Hava yolu Operasyonlarında Planlama ve Çizelgeleme, Pamukkale Uni. Muhendislik Bilimleri Dergisi, Cilt. 16(2), s. 181-191.

[18] Taillard, E.D., Badeau, P., Gendreau, M., Guertin, F., Potvin, J.Y. 1997. A tabu search heuristic for the vehicle routing problem with soft time windows. Transportation Science, Cilt. 31, s. 170-186. DOI: $10.1287 / \operatorname{trsc} .31 .2 .170$

[19] Gendreau, M., Laporte, G., Potvin, J.Y. 2002. Metaheuristics for the capacitated VRP. ss 129-154. Toth, P. ve Vigo, D., ed. 2002. The Vehicle Routing Problem, SIAM Monographs on Discrete Mathematics and Applications. SIAM Publishing, Philadelphia.

[20] Glover, F., Laguna, M. 1998. Tabu Search. In: Du DZ., Pardalos P.M., ed. 1998. Handbook of Combinatorial Optimization. Springer, Boston, MA

[21] Bach, L., Gendreau, M., Wohlk, S. 2015. Freight railway operator timetabling and engine scheduling, European Journal of Operational Research, Cilt. 241(2), s. 309-319. DOI: 10.1016/j.ejor.2014.08.036

[22] Canca, D., Barrena, E. 2018. The integrated rolling stock circulation and depot location problem in railway rapid transit systems, Transportation Research Part E: Logistics and Transportation Review, Cilt. 109, s. 115-138. DOI: 10.1016/j.tre.2017 